\title{
Educação Social de Rua e a Questão da Diversidade Cultural: Quem se Importa? ${ }^{1}$
}

\author{
Street Social Education and the Question of Cultural Diversity: Who \\ Cares?
}

\begin{abstract}
ARMINDO ARMANDO
Doutorando em Língua, Cultura e Sociedade - Universidade Zambeze - Moçambique Docente do Instituto Superior de Ciências e Tecnologia Alberto Chipande, Faculdade de

Ciências Económicas - Beira - Moçambique armandoarmindo21@gmail.com

MARLENE VANESSA MARQUES JAMAL Doutoranda em Língua, Cultura e Sociedade na Universidade Zambeze - Moçambique. Docente da Universidade Licungo - Quelimane. vanessa.jamal@hotmail.com

MARTINS MAPERA Doutor em Estudos Culturais, Director da Faculdade de Ciências Sociais e Humanidades da Universidade Zambeze - Moçambique Professor Associado, autor de vários livros e mentor de programa doutoral de Língua, Cultura e Sociedade. lazifand@gmail.com
\end{abstract}

\begin{abstract}
RESUMO
O presente artigo faz uma análise crítica sobre a situação da educação de rua, em Moçambique, e sua influência no debate em torno da diversidade cultural. Todavia, entende-se que a diversidade cultural constitui uma plataforma de desenvolvimento de uma sociedade, e que o seu estímulo, de diversas formas, é uma abordagem pontual e necessária, principalmente no setor da educação. Entretanto, em Moçambique, por um lado, o Sistema Nacional de Educação dá mais ênfase a educação formal, isto é, institucionalizada, e por outro reconhece a educação informal, setor que não abrange o espaço "rua", desta feita, ignorando completamente o direito à educação das crianças de rua. É neste âmbito que se enquadra o nosso artigo, cujo objetivo é refletir sobre a situação da educação de rua e seu impacto na promoção da diversidade cultural em Moçambique. Para o efeito, recorremos aos métodos hermenêuticos, apoiados pelas técnicas de revisão bibliográfica. Portanto, o artigo conclui que há pouca preocupação de promover a diversidade cultural por meio da educação das crianças de e na rua, pelo que o espaço "rua" é visto como de mendigos e que o direito à proteção e à educação tem sido negados através de políticas públicas que são pouco claras, razão pela qual instamos a quem de direito a sua sensibilidade.
\end{abstract}

Palavras-chave: Educação de rua. Inclusão. Diversidade cultural. Moçambique.

\footnotetext{
${ }^{1}$ Artigo submetido em 16/08/2020 e aprovado em 10/03/2021.
} 
Rev. Interd. em Cult. e Soc. (RICS), São Luís, v. 7, n. 1, p. 80- 95, jan./jun. 2021

ISSN eletrônico: 2447-6498

\begin{abstract}
This article provides a critical analysis of the situation of street education in Mozambique and its influence on the debate around cultural diversity. However, it is understood that cultural diversity constitutes a platform for the development of a society, and that its encouragement, through different forms, is a punctual and necessary approach, mainly in the education sector. However, in Mozambique, on the one hand, the National Education System places more emphasis on formal, that is, institutionalized education, and on the other, it recognizes informal education, a sector that does not cover the "street" space, this time completely ignoring the right the education of street children. It is in this context that our article fits, which aims to reflect on the situation of street education and its impact on the promotion of cultural diversity in Mozambique. For this purpose, we use hermeneutic methods, supported by bibliographic review techniques. Therefore, the article concludes that there is little concern to promote cultural diversity through education in children from and on the street, so the "street" space is seen as a space for beggars and that the right to protection and education has been denied through public policies that are unclear, which is why we urge those entitled to their sensitivity.
\end{abstract}

Keywords: Street education. Inclusion. Cultural diversity. Mozambique.

\title{
CONTEXTUALIZAÇÃO
}

Nos dias que correm, a questão social tem-nos interessado bastante. Eis a razão de pretendermos levar a cabo a pesquisa sobre a Educação Social de Rua e a promoção da diversidade cultural. Verificamos a existência de um número elevado de crianças e adolescentes a deambular pelas ruas das cidades e vilas de Moçambique.

Pretendemos trazer à reflexão desta realidade que às vezes emociona, agride e, muitas vezes, nos causa grande indignação e revolta. Não é fácil ver crianças passarem necessidade num pleno ato de violação dos direitos fundamentais dos seres humanos ${ }^{2}$. Uma criança precisa de amparo, carinho e acolhimento, no seio da sociedade e da família.

Torna-se necessário compreender o contexto de violência que gera o menino ou a menina de e na rua. A "rualização" é consequência de um sistema econômico originário da injustiça, que produz a marginalidade e a pobreza. Este é um cenário de globalização econômica, que compõe a chamada pós-modernidade, e que gera, por um lado, a riqueza mais acentuada e, por outro, a miséria extrema. Desta forma, algo deve ser feito para salvaguardar os direitos das crianças.

\footnotetext{
${ }^{2} \mathrm{O}$ direito à educação, à liberdade, ao respeito e à dignidade, à convivência familiar e comunitária e à cultura são direitos de qualquer pessoa.
} 
Rev. Interd. em Cult. e Soc. (RICS), São Luís, v. 7, n. 1, p. 80- 95, jan./jun. 2021 ISSN eletrônico: 2447-6498

Há, portanto, necessidade urgente de pensar um programa sério de ocupação, destas crianças, e de criar a figura do educador social de rua, em Moçambique. Olhamos para a pedagogia do educador social como uma saída, uma busca, afirmando a cultura da solidariedade.

Estamos conscientes de que os desafios são enormes, mas é preciso começar de algum lado. E, além de mexer mentalidades, algo que leva tempo, é preciso atender, com urgência, essas crianças de rua, por meio de trabalho, de estudo e de criação de ambientes propícios que minimizem a falta de laços afetivos. De igual modo, a questão do respeito e da tolerância em relação às representações culturais necessitam, também, de especial atenção, pois não se faz educação de qualidade sem educação cidadã, educação que valorize acima de tudo a diversidade. É, sim, possível, a nosso ver, aproveitar a diversidade cultural para ensinar a cultura de paz, de respeito ao próximo e à convivência com as diferenças.

Frigotto (1991, p. 87), afirma que, o início de uma pesquisa requer uma problemática e não um problema. Deste modo, levantamos vários questionamentos, mas a questão de base mais genérica é: como resolver o problema de Exclusão Social dos meninos e meninas de Rua em Moçambique respeitando a diversidade cultural?

Em torno disto, várias pesquisas têm sido feitas ao longo do tempo, em alguns países da Europa e América, como Portugal, Brasil e Uruguai e quase nada se escreveu sobre o assunto em Moçambique, particularmente, por isso a nossa preocupação em trazer à tona esta problemática, pois acreditamos ser de suma importância.

No Brasil, por exemplo, em 2016 a autora Paula Marçal Natali publicou trabalhos relacionados à Formação Profissional na Educação Social: subsídios a partir de Experiências de Educadores Sociais Latino Americanos. Outra autora de referência, ainda no mesmo país, é Juliana Santos Graciani, com várias obras e pesquisas relacionadas à Prática Educativa à Luz da Pedagogia Social e da Psicologia Social Comunitária: Estudo do Programa Integração AABB Comunidade em 2015. Em Portugal, a autora Matilde de Jesus Sirgado, também no mesmo ano, pesquisou sobre Crianças em Situação de Rua: O Caso do IAC - Projecto Rua "Em Família para Crescer", dentre outros estudos.

Neste âmbito, compreendemos que o estudo é importante para a área de educação, cultura e sociedade visto que traz uma reflexão que chama à razão a 
Rev. Interd. em Cult. e Soc. (RICS), São Luís, v. 7, n. 1, p. 80- 95, jan./jun. 2021

ISSN eletrônico: 2447-6498

responsabilidade humanitária que cada ser humano deve ter para os que sofrem e que precisam de asilo sociocultural. Por outro lado, perpetuamos um pensamento de que as intervenções sociais para com as crianças de rua e da rua devem se basear no respeito aos valores que os caracterizam, podendo a sua ação ser libertadora e não opressora face aos padrões éticos da sociedade. Num mundo negacionista em que vivemos, é importante ressaltar que este artigo imputa a responsabilidade de todos nós, no que se refere à missão de promover a diversidade cultural em diferentes extratos sociais e consolidar a convivência serena.

Portanto, para o desenvolvimento do estudo, usamos o método bibliográfico que consistiu na revisão bibliográfica para a sustentação teórica. Por outro lado, usamos também a técnica de análise documental dos relatórios institucionais e do quadro legal da diversidade cultural e proteção de crianças de rua e, por fim, fizemos um estudo empírico, trazendo estudos similares em outros países para aplicação do método comparado. Desta feita, os métodos assim como as técnicas permitiram consolidar os resultados do artigo, o que faz com que os seus objetivos sejam atingidos.

\section{PRESSUPOSTOS TEÓRICOS DA EDUCAÇÃO SOCIAL DE RUA}

Um dos objetivos fundamentais da Educação Social de Rua é exaetamente o de estimular estas crianças a discutirem, entenderem e aceitarem de forma digna as regras e os limites necessários ao exercício da cidadania.

Para sua total efetivação, a Pedagogia Social de Rua precisa de dois requisitos fundamentais: uma equipe interdisciplinar competente e flexibilidade pedagógica. A Educação Social de Rua tem como principal objetivo garantir o respeito à identidade cultural da criança de rua, a partir da apropriação e da produção de conhecimentos relevantes e significativos para eles, de forma crítica, numa perspectiva de compreensão e transformação da realidade pessoal e social.

Como sustenta Cardoso (2001, p. 13),

No que se refere à igualdade de oportunidades educativas, espera-se que a escola e os professores, na sua tarefa de educar para uma cidadania democrática e interdependente, estejam atentos às complexidades dos movimentos demográficos, às novas realidades 
Rev. Interd. em Cult. e Soc. (RICS), São Luís, v. 7, n. 1, p. 80- 95, jan./jun. 2021

ISSN eletrônico: 2447-6498

sociais, à intensificação das relações cada vez mais próximas, entre culturas, povos e pessoas e acima de tudo, tenham em conta as flagrantes situações de desigualdade e injustiça social e a consciência, cada vez mais generalizada do direito, de cada um à igualdade de tratamento e à afirmação das suas diferenças.

Embora não haja medidas concretas na definição do nosso sistema educativo, relativamente, na educação social de rua, há defesa de alguns princípios filosóficos desse tipo de educação. De acordo com a FDC (2009), Moçambique aprovou, em 2008, três importantes leis para proteção à criança, a citar: a Lei de Promoção e Protecção dos Direitos da Criança; a Lei de Prevenção e Combate ao Tráfico de Pessoas e as Leis de Organização Tutelar de Menores.

Na Lei n. ${ }^{\circ}$ 7/2008 de 9 de Julho, Lei de Promoção de Protecção dos Direitos da Criança, especificamente os artigos 40 e 68 afiançam que o Estado tem o dever de criar, de forma progressiva, condições para que seja assegurado à criança o ensino básico, obrigatório e gratuito, atendimento ao ensino primário, por meio de programas suplementares de material didático-escolar. Já no artigo 68, o Governo deve adotar medidas de atendimento especial adequado, incluindo legislativas, administrativas, sociais e educativas tendentes à proteção das crianças em situação difícil ou de risco. Mais uma vez se testam os direitos fundamentais das crianças (que a nosso ver têm sido violados).

Existem várias definições de políticas públicas, mas achamos pertinente trazer algumas no sentido de clarificar o nosso pensamento. Para Brancaleon et al. (2015), são áreas onde o Estado tem de interferir para o alcance de um estado almejado, que se presuma melhor. Por isso, trata do problema da saúde, educação, economia, setor elétrico, justiça, etc. Por sua vez, Saraiva e Ferrarezi, (2006, p. 28),

Definem política pública como um fluxo de decisões públicas, orientado a manter o equilíbrio social ou a introduzir desequilíbrios destinados a modificar essa realidade. Decisões condicionadas pelo próprio fluxo e pelas reacções e modificações que elas provocam no tecido social, bem como pelos valores, ideias e visões dos que adoptam ou influem na decisão.

É necessário destacar que Moçambique esteve sob a dominação colonial portuguesa, que introduziu o sistema de educação formal, no séc. XIX. Até 1975, tal sistema, assumia um caráter segregacionista e elitista, visando reproduzir e promover as 
Rev. Interd. em Cult. e Soc. (RICS), São Luís, v. 7, n. 1, p. 80- 95, jan./jun. 2021

ISSN eletrônico: 2447-6498

desigualdades dentro do sistema colonial. No período pós-colonial, assiste-se à criação de um sistema educacional que tinha como pano de fundo, numa primeira etapa, a perspectiva de formação do Homem Novo, no contexto dos princípios do socialismo científico e, numa segunda, a partir da segunda metade da década de 80 do séc. XX até à atualidade, a adoção dos princípios do neo-liberalismo. Portanto, a questão do separatismo, elitismo e desigualdades absurdas e inenarráveis, herdados da era colonial, parecem continuar a respingar em nós.

É preciso compreender que o direito de ser criança enfrenta outras barreiras, além da frequência a uma instituição que respeite sua condição específica, pois, numa sociedade consumista como a nossa, torna-se cada vez mais difícil aceitar o outro. A educação é um direito de todos e do Estado, entretanto vale questionar, será que o Estado estará apto e disponível para oferecer uma educação cidadã aos meninos e meninas de rua?

Na América Latina, o Uruguai destaca-se como um país cujo sistema público da Educação Social é organizado e reconhecido socialmente. Assim, conhecer a constituição e as características daquela realidade pareceu-nos fundamental, pois nos permitiria aprender com uma experiência consolidada, em uma instância da educação cuja concretização ainda se pretende buscar em Moçambique.

No Uruguai, segundo (RIBEIRO, 2006 apud NATALI, 2016, p.20), a Educação Social “[...] começa a estruturar-se em 1985 dentro do processo de redemocratização do país, que se encontrava, como o Brasil, num regime de ditadura”. A formação inicial de educadores sociais se oficializa em nível terciário (a formação terciária é a formação não universitária realizada após o término do ensino médio no Uruguai) e é reconhecida pelo Ministério da Educação e de Cultura uruguaio desde 1997.

Em razão das profundas mudanças sociais ocorridas nos últimos tempos, a educação precisa acompanhar tal fluxo e, ao mesmo tempo, dar respostas eficazes aos novos desafios que se impõem. Neste contexto, precisamos de profissionais de educação comprometidos com os ideais da justiça social, profissionais estes que trabalharão diretamente com indivíduos, em situação de vulnerabilidade socioeconômica, exercendo, deste modo, um papel de destaque na construção de uma sociedade mais justa. 
Rev. Interd. em Cult. e Soc. (RICS), São Luís, v. 7, n. 1, p. 80- 95, jan./jun. 2021 ISSN eletrônico: 2447-6498

É imperioso que o governo moçambicano se desafie e passe a pensar na possibilidade de criar espaço para que, realmente, a Educação seja para todos, sem exceção, como é o caso dos meninos e meninas de rua. Que o Sistema Nacional de Educação moçambicano olhe, com muita atenção, para o assunto e comece a idealizar estratégias urgentes, de modo que se parta para a concretização e materialização deste sonho para muitas crianças e adolescentes de rua.

Acreditamos que a sociedade precisa refletir e, de forma consciente, sobre a emergência do assunto em questão, pois como afirma Serra (2014, p. 43) "[...] quanto mais se agravarem os sintomas da exclusão social, maiores serão as possibilidades das crises sociais, maiores serão os capitais de estigma e de desqualificação e maiores os riscos de violência social”.

Com todo cenário descrito, acreditamos que a educação Social de Rua, em Moçambique, é, sim, uma utopia realizável. É importante que se quebre a barreira existente entre os dois Ministérios que devem garantir a execução desse projecto, o Ministério do Gênero, Mulher e Ação Social e o da Educação e Desenvolvimento Humano.

É fundamental que se unam para garantir a inclusão dessas crianças no processo educativo. Portanto, entendemos que diante do atual cenário que o país vive, urge que se defina, no sistema educativo, um currículo que traga claramente uma abordagem multi/intercultural. Impõem-se, portanto, novas abordagens sobre a inclusão e a diversidade cultural e, dessa forma, contribuir para que as práticas pedagógicas, dentro e fora da escola, comecem primando por um ensino que valorize e respeite a diversidade da sua população, e, muito mais, crie condições para que haja interaeção entre as várias culturas.

\section{ORGÂNICA E ESTRUTURA DO SISTEMA NACIONAL DE EDUCAÇÃO VIGENTE EM MOÇAMBIQUE}


Rev. Interd. em Cult. e Soc. (RICS), São Luís, v. 7, n. 1, p. 80- 95, jan./jun. 2021 ISSN eletrônico: 2447-6498

O sistema Nacional de Ensino em Moçambique-foi revisto em 2018, ao abrigo da Lei sobre Sistema Nacional de Educação, da constituição da República de Moçambique, Art. 178. Ele visava adequar-se aos novos desafios socioeducativos que caracterizam Moçambique na atualidade.

A lei estabelece um regime jurídico do sistema nacional de educação baseado no território moçambicano cuja aplicação é de todas instituições de ensino que complementam o Sistema Nacional de Ensino.

Na $1^{\text {a }}$ Secção da Lei orgânica que rege o SNE, estabelece-se a estrutura dos subsistemas de educação constituída por seis (06) subsistemas, dentre eles, destacam-se: educação pré-escolar; educação geral; educação profissional, educação e formação de professores e ensino superior.

A educação pré-escolar é a realizada em creches e jardins de infância para crianças com idade inferior a 6 anos, como complemento da ação educativa da família com a qual as instituições cooperam estreitamente.

A lei do SNE, entende a Educação Geral como eixo central do sistema de educação que confere a formação integral, base para o ingresso em cada nível subsequente dos diferentes subsistemas. Quanto à estratificação, entendemos que o Subsistema de Educação Geral compreende: o ensino Primário e o ensino Secundário.

No que tange aos objetivos, o SNE estabelece que a educação Geral deve proporcionar o acesso ao ensino de base ao cidadão, contribuindo de modo a garantir a igualdade de oportunidades de acesso, aos sucessivos níveis de ensino e ao trabalho; garantir uma formação integral ao cidadão para que adquira e desenvolva conhecimentos e capacidades intelectuais, físicas e uma educação estética e ética; assegurar uma formação que responda às necessidades; conferir ao cidadão conhecimentos, desenvolvendo nele capacidades, hábitos e atitudes necessários à compreensão e participação na transformação da sociedade; preparar o cidadão para o estudo e trabalho independentes, desenvolvendo as suas capacidades; desenvolver uma orientação vocacional que permita a harmonização entre as necessidades do País e as aptidões individuais. 
Rev. Interd. em Cult. e Soc. (RICS), São Luís, v. 7, n. 1, p. 80- 95, jan./jun. 2021 ISSN eletrônico: 2447-6498

O ensino primário é o nível inicial de escolarização da criança, no qual adquire conhecimentos, habilidades, valores e atitudes fundamentais para o desenvolvimento harmonioso da sua personalidade.

O Ensino Primário realiza-se em duas modalidades: modalidade monolíngue, em língua portuguesa, e modalidade bilíngue, em língua moçambicana, incluindo a língua de sinais e portuguesa. Portanto, o Ensino primário compreende seis classes, organizadas em dois ciclos de aprendizagem: a) $1 .^{\circ}$ ciclo, $1 .^{a}$ a $3 .^{a}$ classe; b) $2 .^{\circ}$ ciclo, $4 .^{a}$ a $6 .^{\mathrm{a}}$ classe.

No $\operatorname{Art}^{0} .13$, da lei orgânica, o Ensino Secundário é o nível pós-primário em que se ampliam e aprofundam os conhecimentos, habilidades, valores e atitudes para o aluno continuar os seus estudos, inserir-se na vida social e no mercado de trabalho.

Quanto à organização, a lei prevê que o Ensino Secundário compreende seis classes organizadas em dois ciclos de aprendizagem, como o do $1^{\circ}$ ciclo, da $7 .^{\text {a }}$ a $9 .^{\text {a }}$ classe e $2^{\circ}$ ciclo, da $10 .^{a}$ a $12 .^{a}$ classe.

A Educação de adultos é o subsistema em que se realiza a alfabetização e educação para o jovem e adulto, de modo a assegurar uma formação científica geral que permita o acesso a vários níveis de educação; técnico-profissional, ensino superior e formação de professores.

A formação conferida por este subsistema corresponde a que é dada pelo subsistema de educação geral, devendo ser adequada às necessidades de desenvolvimento socioeconômico do País. Portanto, o Subsistema de Educação de Adultos compreende o ensino primário e o ensino secundário.

Quanto aos objetivos da educação de adultos, destacamos: assegurar o acesso à educação do jovem e do adulto que não tenham tido a oportunidade de efetuar os estudos na idade regular e proporcionar formação científica geral que confira competências necessárias para o desenvolvimento integral, sentido de responsabilidade individual e coletiva e aprendizagem ao longo da vida.

A lei orgânica do SNE entende que o Subsistema de Educação e Formação de Professores regula a formação de professores para os diferentes subsistemas. A educação e formação de professores compreendem: a Educação e Formação de Professores para o ensino pré-escolar; a Educação e Formação de Professores para o 
Rev. Interd. em Cult. e Soc. (RICS), São Luís, v. 7, n. 1, p. 80- 95, jan./jun. 2021

ISSN eletrônico: 2447-6498

ensino primário; a Educação e Formação de Professores para o ensino secundário; a Educação e Formação de Professores para o ensino técnico-profissional; a Educação e Formação de Professores para a educação de adultos e Educação e Formação de Professores para o ensino superior.

Ao Ensino Superior compete assegurar a formação ao nível mais alto nos diversos domínios do conhecimento técnico, científico e tecnológico necessário para o desenvolvimento do País. O ensino superior destina-se aos graduados da $12 .^{a}$ classe do ensino geral ou equivalente.

\section{CULTURA E RUA: MUNDO SUBALTERNO AO SNE EM MOÇAMBIQUE}

Para entender a cultura, é importante conceituá-la baseando-se nas teorias da evolução, assim como nas teorias geográficas como o determinismo, possibilismo que influenciaram para que, vários conceitos tivessem um posicionamento específico.

O conceito cultura provém do termo Germânico: Kultur que servia para simbolizar todos os aspectos imateriais de uma comunidade, pelo que a sua evolução implicou a concepção na palavra Francesa Civilization que se refere as realizações materiais de um povo, (LARAIA, 2001, p. 19-20).

A concepção de Laraia (2001) concebe-se a partir de Taylor (1832 - 1917), a ideia de que o conceito de cultura se torna amplo sentido das atribuições sociais que, dentre eles, destacam-se a inclusão de conhecimentos, crenças, arte, moral e leis, costumes, qualquer outra capacidade ou hábitos adquiridos pelo homem como membro de uma determinada sociedade.

De forma habitual, a cultura é concebida como formas e estilos de vida. Entretanto, elas são baseadas nas abordagens mais tendenciais para a sua formação, como a base de construção de toda síntese sobre a identidade social pela qual a sociedade poderá se orientar.

Numa visão antropológica sobre a educação de rua, o conceito de cultura ganha uma dinâmica inovadora baseada no contexto estruturalista antropológico. A cultura é entendida como o conjunto das relações sociais que servem de modelo estruturante de 
Rev. Interd. em Cult. e Soc. (RICS), São Luís, v. 7, n. 1, p. 80- 95, jan./jun. 2021

ISSN eletrônico: 2447-6498

um determinado modo de vida. Desta feita, o perfil, o comportamento e o modo de vida de crianças sem-abrigo, que se encontram a morar na rua, representam uma nova cultura, que implica, em várias vezes, a sociedade não dar conta do espaço desta manifestação da prática cultural.

A concepção de Levi-Strauss (1976) sobre a cultura como um conjunto dos três códigos estruturais das relações sociais como a economia, parentesco e signos, estabelece uma relação intercultural baseada no valor econômico, vinculando o processo ideológico como vital nas relações interpessoais e interculturais. Esta concepção, traz uma nova dinâmica social de intervenção cultural mediados por três elementos chaves, dos quais buscam desenvolver-se através de modelos econômicos de um mercado sem lógica em busca da sobrevivência.

Neste contexto, a cultura pode ser considerada de todo valor que identifica um indivíduo, resultado da educação familiar, entre os valores geneticamente pré-existentes e socialmente transmitidos, com vista a dar identidade social.

O debate sobre a cultura resultar da educação familiar, implica o desenvolvimento de modelos educacionais que não se ajustam à realidade sobre a humanidade, ou seja, a educação é usada como instrumento de construção da diversidade econômico-social e não como espaço de humanização social.

\section{DIVERSIDADE E LEGITIMIDADE DO LUGAR "RUA" NA EDUCAÇÃO SOCIAL}

Ao longo da história, a diferença existe e sempre existiu. Todavia, o conceito de diversidade foi atribuído, de forma especial, à raça e gênero. Com o tempo, esta restrição ganhou abertura para uma nova abordagem baseada em fatores diferenciados. Tal como atesta Hanashiro, Goody e Carvalho (2004), acrescem-se teoria da Identidade Social, Teoria das Relações intergrupais, Demografia Organizacional, teoria da assimilação e teoria etnográfica.

A teoria da assimilação representada por Kraigere Ford (1985), Morisson (1987), Greenhauss (1990), Bele (1990), Thomas (1990), Cox e Nkomo (1991), compreende que a diversidade aparece ao analisar o tratamento diferenciado nas organizações 
Rev. Interd. em Cult. e Soc. (RICS), São Luís, v. 7, n. 1, p. 80- 95, jan./jun. 2021

ISSN eletrônico: 2447-6498

baseados na raça, etnia, género bem como descriminação racial e sexual (Nkomo\& Cox Jr, 1999).

Contudo, aparece, neste estudo, uma dimensão que o autor não avança, que é a questão da descriminação social como fonte de definição da diversidade. No entanto, numa perspectiva positivista, pode-se olhar esta realidade como veículo para sustentar o conceito diversidade. Portanto, estas acções não são adequadas para especificar a sua influência teórica, pois trata-se de uma diversidade baseada na descriminação.

A concepção mais adequada sobre o fato de a educação de rua ser uma plataforma de avaliação da diversidade, tem a ver com o entendimento de Falcão (2017: 36) que entende como "factor que se estende desde a idade, história pessoal, corporativa, formação educacional, função e personalidade". Assim, numa sociedade em que a educação de rua continua sendo uma opção subalterna às instituições e estrutura social de formação do homem, é importante que a reflexão seja pragmática, junto dos fazedores de políticas educativas, particularmente.

Taguieff (1997) e Wieviorka (1992, p.95 citados por CABECINHAS, 2007) entendem que a distinção entre nós e os outros implica o reconhecimento de uma diferença, e essa diferença nunca é neutra: pode provocar repulsa, receio, inquietação ou atração.

Olhando para a educação de rua, no nosso contexto, compreende-se que as relações interpessoais, no dia-a-dia, têm sido fator determinante para a evidência da diversidade, visto que as desigualdades sociais buscam aferir o quão a diferença deve ser objeto de respeito na sociedade. Portanto, a questão da diferenciação se torna o conceito mais próximo da diversidade e que permite encontrar uma alternativa de todos conceitos apresentados.

Em Moçambique, o sistema educacional é cada vez mais elitizado, apesar dos esforços na construção de mais escolas que devem fazer face ao desenvolvimento do país, pois a valorização de uma educação formal baseada em instituições políticas, assim como em instituições sociais tradicionalmente aceitas, faz com que o lugar "rua" continue sendo um espaço de exclusão social sem uma linguagem própria que permita a intervenção. 
Rev. Interd. em Cult. e Soc. (RICS), São Luís, v. 7, n. 1, p. 80- 95, jan./jun. 2021 ISSN eletrônico: 2447-6498

As políticas públicas,-sobre a criança de rua estão voltadas para recuperação dos mesmos e trazê-los de volta para a sociedade. Entretanto, estas dimensões fazem com que haja maior credibilidade nas instituições formais em relação a rua. A exclusão nestes moldes acontece a partir do momento em que não se aceita o modo de vida dos outros, considerando-os como "marginais", pois vivem fora do paradigma previamente estabelecido.

$\mathrm{Na}$ sociedade atual, em que a diversidade é objeto de exaltação para o desenvolvimento de uma comunidade, é importante que os atores de cada ação social estejam vinculados com as políticas públicas que visam reconhecer o mundo alheio e ajudá-lo a construir, estimulando a diferença, olhando para a seguinte concepção:

A diversidade é respeitar nossas diferenças, maximizando nossos potenciais individuais, e valorizar nossos singulares enquanto regozijamos nossas experiências e talentos colectivos para crescimento; é inclusão, respeito pelo individuo, valorizando e capitalizando as diferenças, (HAYLE; RUSSEL, 1997, p. 11- 13).

A diversidade deve ser entendida como momento pelo qual um indivíduo respeita as dimensões naturais e sociais do outro, como um ser detentor de valores para o crescimento individual. No quadro educacional, é imperioso que sejam criadas as políticas específicas para a materialização destes elementos, razão pela qual, o espaço "rua" deve ser aberto do seu enquadramento para a promoção da educação social de rua.

No entanto, compreende-se no artigo, que em Moçambique não existe uma política educativa orientada às crianças de rua e na rua que possa sustentar a lógica educativa que garanta direitos às crianças por meio do processo de ensino e aprendizagem. Todavia, na falta de pessoal preparado para lidar com as crianças de rua e na rua através de uma pedagogia da libertação, impera o fraco nível de intervenção das políticas sociais de redução da vulnerabilidade, faltando integração coletiva das crianças no sistema nacional de Educação.

Nestes pressupostos, verifica-se também um dado curioso, no que se refere às questões de gênero das crianças de e na rua, visto que maior parte delas são do gênero masculino, fato que permite compreender o não favorecimento para com a igualdade das políticas de proteção social de crianças orientadas para as questões de gênero, e que elas estão, sim, orientadas para o gênero feminino. 
Rev. Interd. em Cult. e Soc. (RICS), São Luís, v. 7, n. 1, p. 80- 95, jan./jun. 2021 ISSN eletrônico: 2447-6498

O contexto socioeconômico de rua, caracterizado por falta de políticas exequíveis para a integração social das crianças, compromete a consolidação da diversidade cultural em Moçambique, pois as relações interpessoais entre as crianças de rua e na rua com outros atores sociais são basadas na vilipendiação dos mesmos, não dando espaço para a manifestação dos valores socioculturais das crianças por meio da valorização da diferença.

\section{CONSIDERAÇÕES FINAIS}

Conforme explicitado inicialmente, este artigo pretendeu trazer um olhar crítico sobre a Educação Social de Rua e a Questão da Diversidade Cultural: quem realmente se importa com a questão da exclusão social a que as crianças de e na rua estão sujeitas.

Numa sociedade em que a educação de rua continua a ser uma opção subalterna às instituições e estrutura social de formação do homem, é importante que a reflexão seja pragmática junto dos fazedores de políticas, pois, o perfil, o comportamento e o modo de vida de crianças sem-abrigo, e que se encontram a morar na rua, representam uma nova cultura que, várias vezes, a sociedade não se dá conta do espaço desta manifestação da prática cultural. Acreditamos que a sociedade precisa refletir, de forma consciente, sobre a emergência do assunto em questão, pois a exclusão social origina crise social e aumenta as possibilidades de violência social.

Considerando que as políticas públicas educativas e de proteção das crianças não estão orientadas de forma clara para crianças de rua e na rua, concluímos que a sociedade dá pouca importância sobre a educação de rua e desvaloriza a questão da diversidade cultural, com base nos valores socioculturais das pessoas com pouco acesso aos serviços sociais públicos e privados.

É a nosso ver, imperioso, que o Governo moçambicano se desafie e passe a pensar na possibilidade de criar espaço para que, realmente, a Educação seja para todos, sem exceção; que o Sistema Nacional de Educação olhe, com muita atenção, para o assunto e comece a idealizar estratégias urgentes de modo que se materialize este sonho para muitas crianças e adolescentes de rua. 
Rev. Interd. em Cult. e Soc. (RICS), São Luís, v. 7, n. 1, p. 80- 95, jan./jun. 2021 ISSN eletrônico: 2447-6498

Parafraseando Freire (2000), na linha destas reflexões há uma exigência fundamental, um ponto de partida sem o qual nada é possível e que se coloca não apenas à educação de adultos, mas à educação em geral. Portanto, acreditamos que mudar é difícil, mas é possível. Com todo cenário descrito pensamos que a educação Social de Rua, em Moçambique, é sim uma utopia realizável.

A falta de dados estatísticos claros, de políticas específicas claras para as crianças de e na rua, de clareza legislativa sobre estratégia de intervenção para esta camada social, dificultou a realização do estudo, pois não se poderia esperar um artigo de alta magnitude em termos de dados comparativos sobre a evolução desta camada social e a eficácia ou ineficácia de políticas educacionais orientadas à criança de rua.

Portanto, é imperioso que os outros estudiosos considerem importante o aprofundamento de questões de gênero, sobretudo das crianças de e na rua para melhor apontar as causas do desequilíbrio e o impacto nas políticas públicas sociais em Moçambique, que implicam fragilidade na promoção da diversidade cultural.

\section{REFERÊNCIAS}

ARRUDA, Ricardo. et al, A. O que é Exclusão Social? Lisboa. Escolar Editora, 2014.

BRANCALEON, Brigida, Baptista., et al. Políticas públicas: conceitos básicos. São Paulo: Universidade de São Paulo, 2015.

CABECINHAS, Rosa. Preto e Branco: A Naturalização da Discriminação Racial. Humus Editora, CECS, Universidade do Minho, Braga, Portugal, 2017.

CONSELHO DE MINISTROS. Estratégia do Ensino Secundário Geral, 2009-2015.

FALCAO, B, M. Diversidade e Desempenho Académico: Percepções dos estudantes de Administração. (Universidade FUMEC - Dissertação de Mestrado). Belo Horizonte, Brasil, 2007.

FUNDAÇÃO PARA O DESENVOLVIMENTO DA COMUNIDADE (2009). Projecto de Promoção dos Direitos da Criança - Divulgação das Leis de Protecção da Criança, 2009.

HANASHIRO, Goody. \& QUEIROZ, Ricardo. Estudos em diversidade: Reflexões Teorias e Evidências Práticas, III Encontro de estudos Organizacionais. Brasil, 2004.

LARAIA, Roque. Cultura, Um Conceito Antropológico. 14ª Ed., Rio Janeiro - Brasil. 2001. 
Rev. Interd. em Cult. e Soc. (RICS), São Luís, v. 7, n. 1, p. 80- 95, jan./jun. 2021 ISSN eletrônico: 2447-6498

NATALI, Paula. Formação Profissional na Educação Social: Subsídios a partir de experiências de Educadores Sociais Latino Americanos - Universidade Estadual de Maringá, Maringá, 2016.

NKOMO, Stella M.; COX JR., Taylor. Diversidade e identidade nas organizações. In: CLEGG, Stewart R.; HARDY, Cynthia; NORD, Walter R. (Org.). Handbook de estudos organizacionais: modelos de análise e novas questões em estudos organizacionais. São Paulo: Atlas, 1999. v. 1. cap. 12, p. 334-360.

SARAIVA, Enrique e FERRAREZI, Eisabete. Políticas Públicas: dos clássicos às modernas abordagens. In Políticas Públicas (Vol. 1). Brasília: Escola Nacional de administração pública, 2006.

UNESCO. Declaração Universal Sobre a Diversidade Cultural. www.unescodoc.org/images/0012/0071/127160por.pdf Acesso: 20.07.2020: 21:16', 2011. 